\title{
A VISÃO DO HOMEM NA OBRA TSUREZUREGUSA: A RECLUSÃO RELIGIOSA E O IROGONOMI
}

Toshiko Imazeki*

Tsurezuregusa $a^{1}$ é um ensaio do século XIV, que corresponde na divisão história do Japão à Idade Média. $O$ seu conteúdo abrange variados temas e nele pode-se perceber um profundo discernimento do ser humano e a rica natureza humana do autor.

A propósito, o seu autor, Kenkô, é um eremita budista 2 . A Idade Média foi uma época em que os eremitas budistas exerceram grande atividade. Não se pode pensar na cultura da Idade Média, ignorando a classe dos eremitas que optaram pela reclusão religiosa. Eles foram o sustentáculo da realização literária e a sua literatura $e$, por vezes, denominada sôan bungaku (literalmente, "Literatura de cabana") ou inja bungaku (literalmente, "Literatura de eremita"). Desnecessário dizer que o eremita segue o Caminho da Verdade (O Caminho de Buda) e abandona o mundo terreno, podendo ser considerado três tipos deles: o primeiro tipo é o eremita que se embrenha nas montanhas e vive recluso numa cabana e pode ser representado por Kamo no

- Professora visitante da Universidade Feminina Teikoku, Japão, junto à Faculdade de Filosofia, Letras e Ciências Humanas da USP.

1. Tsurezuregusa (Ensaios no Ócio) - escrito no século XIV por Urabe no Kaneyoshi, mais conhecido por Kenkô, nome adotado depois de se tornar monge budista. (N. da T.)

2. Eremita budista - tonseisha, inja ou yosutebito, em japonês. Refere-se à pessoa que não pertence à classe clerical, mas presta seu voto ao Budismo, e vive isolado da sociedade numa rígida demonstração de desprendimento e desapego às coisas materiais. A profusāo de eremitas budistas ocorreu na Idade Média (séculos XII - XVI), no Japão. (N. da T.) 
Chômei; o segundo tipo é aquele que peregrina por várias localidades e pode ser representado por Saigyô; o terceiro tipo é aquele que permanece na cidade. O representante desse último tipo é Kenkô, o autor de Tsurezuregusa. Contudo, mesmo o eremita que peregrina por vários lugares pode chegar a morar numa cabana, assim como Kenkô, que morava na cidade, chegou a viver recluso nas montanhas, não sendo possível delimitar rigidamente os três tipos. A classificação acima serve apenas, portanto, como uma referência padrão relativa ao comportamento dos eremitas budistas.

$O$ que os identifica é o fato de não serem monges ascetas vinculados a um templo e o fato de abandonarem todos os prazeres da vida terrena, tais como a posição social, a fama, a familia e permanecerem isolados do mundo. E esse modo de vida chegou a se tornar um ideal na época medieval japonesa.

Pelo ponto de vista atual, a imagem desses eremitas é normalmente ligada à de severos praticantes budistas, mas a realidade da época difere muito da imagem de hoje.

Em se tratando, por exemplo, de Saigyô, admirado em épocas posteriores (haicaístas como Bashô, do século XVII, não escondem a admiração por ele), notabilizou-se por demais como poeta, e os temas poéticos preferidos por Saigyô, que foi também um eremita budista, foram a "flor", a "lua" e o "amor", temas aparentemente contraditórios com a prática budista. Também Kenkô, denominado, "um dos quatro melhores"3, era reconhecido pelo círculo poético da época e em sua antologia são constantes os poemas que cantam o amor. Na sua obra Tsurezuregusa depara-se facilmente com descrições concernentes à sua concepção de mulher. Cabe lembrar, inicialmente, que no eremita budista Kenkô existe uma face, a da aceitação do irogonomi ${ }^{4}$, que, à primeira vista, contrapõe-se à reclusão religiosa.

Inicialmente, torna-se necessário deixar claro o conceito de irogonomi. O significado atual da palavra irogonomi é extremamente vago. De modo geral, é usada simplesmente com o sentido de "namoradeira", "mulherengo", "sentimentalidade", onde a atitude leviana e de prazer estão fortemente presentes e, em casos extremos, engloba forte conotação negativa, sendo utilizada até como sinônimo de "maníaco sexual", não podendo ser considerada, no mínimo, como palavra de elogio.

3. Os quatro maiores poetas da era medieval foram: Ton'a, Jôben, Keiun e Kenkô. (N. da T.)

4. Preterimos manter a palavra irogonomi, sem traduzi-la, por não haver em Língua Portuguesa um termo que condense, por si só, o sentido exato do japonês. "Sedução", "sedutor" seria uma tradução aproximada, porém insuficiente. Irogonomi indica a sedução no sentido positivo, englobando não só a beleza física, o fascínio pessoal, mas também o refinamento, a sensibilidade, o profundo conhecimento cultural etc. (N. da T.) 
Vejamos o seu significado no Grande Dicionário da Língıa Japonesa:

1. entrega-se voluntariamente à relação com o sexo oposto. Comprecnder perfeitamente os prazeres relacionados com o amor, romance. Ou essa

2. ter interesse ou o conhecimento direcionados não para o que é prático, mas para o que é refinado ou elegante

3. o fato de comprar cortesãs. Ou ainda essa cortesã.

O significado de irogonomi da Antigüidade (séculos VIII-XII) e da Idade Média (séculos XII-XVI) difere muito da atualidade. Aproxima-se dos sentidos 1 e 2 do Grande Dicionário da Língua Japonesa, mas essa explicação é ainda insuficiente. Irogonomi da Antigüidade e da Idade Média não define apenas o sujeito que sente uma atração desmedida pelo sexo oposto. Além disso, a palavra irogonomi não possui conotação negativa e sim, positiva.

Como representantes do irogonomi da Antigüidade podemos citar nomes como Minamoto no Tôru, Ariwara no Narihira e Ono no Komachi. Trata-se de personagens reais da Antigüidade, mas seus dados biográficos não são conhecidos detalhadamente e os dados que possuímos são fictícios. A imagem posteriormente criada é a que se consagrou e exerceu influência. Minamoto no Tôru, descrito em Ise Monogataris como tenno shitano irogonomi (aproximadamente "o homem mais sedutor da terra") construiu a suntuosa residência conhecida como Kawara no in, desfrutou de uma luxuosa vi$\mathrm{da}$, foi o ídolo dos nobres da época posterior e é apreciado como protagonista principal da peça do teatro Nô, Tôru. Narihira e Komachi foram poetas da época de Kokinsh $\hat{u}^{6}$ e, como personificações de um amor carregado de emoções, tiveram uma atuação vistosa. Entre os personagens fictícios, Hikaru Genji, o protagonista de Genji Monogatari', pode ser apontado como representante máximo do irogonomi.

Levantando-se as particularidades comuns aos irogonomi acima citados, para precisar o seu sentido, temos:

1. são belos

2. exercem um fascínio sobre o sexo oposto e são diligentes com relação ao amor

3. pertencem a famílias de boa linhagem, são nobres. Têm relação com a familia imperial

4. possuem uma sensibilidade privilegiada e uma cultura admirável para compreender o belo e o refinado.

5. Ise Monogatari - narrativa poética, escrita aproximadamente no fim do século IX. (N. da T.)

6. Kokinsha - a primeira das 21 antologias poéticas organizadas sob a ordem imperial. Foi organizada aproximadamente no século X. (N. da T.)

7. Genji Monogatari - narrativa clássica escrita aproximadamente no século XI pela dama da corte Murasaki Shikibu. (N. da T.) 
Ou seja, irogonomi é a concepção relacionada com o fascínio existencial do homem e com o seu modo de ser ideal, e preencher todos os requisitos acima citados, para ser considerado um deles, é bastante difícil.

A escritora Fumiko Enji chamou de shumi ren'ai ${ }^{8} 0$ amor dos nobres da Antigüidade. Shumi ren'ai reflete justamente o mundo próprio do irogonomi. $O$ amor daquela época inicia-se com a troca de poemas. $O$ papel utilizado para cada ocasião era examinado e escolhido de acordo com a estação do ano, a condição dos amantes, o estado de espírito, para só então escrever aí o poema numa elegante caligrafia. Conforme a estação, o poema era ainda amarrado num galho florido com róseas ameixeiras, cerejeiras ou num galho outonal com folhas de um vermelho-fogo, como expressão da paixão. Quando o amor findava, crisântemos murchos podiam acompanhar o poema. Esses elaborados artifícios seriam impraticáveis para aqueles que só pensam na praticidade, necessitando, digamos, de uma disponibilidade para apreciar o supérfluo da vida, sendo indispensável uma profunda e refinada bagagem cultural.

Acrescentaremos ainda que os representantes do irogonomi possuem um certo elemento dramático. Kawara no in, palco da prosperidade de Minamoto no Tôru, transformou-se numa ruína decadente; Narihira, vítima do infortúnio, foi enviado para o exilio, no Leste; Komachi, considerada uma das mais belas jovens da sua época, acaba seus dias como uma pobre errante. Também Hikaru Genji sofre as desgraças de um exilio em Suma e fica difícil afirmar se ele, que conquistou tudo que quis durante a sua vida, foi feliz ou não. Os representantes do irogonomi, por serem privilegiados, carregam consigo a tendência para a ruína e a destruição. Ou seja, pode-se dizer que a essência do irogonomi está no fato de aproveitar profundamente a breve vida, carregando a sina de, um dia, cair infalivelmente em desgraça.

Pelo acima exposto, o ermitão Kenkô não nega o irogonomi. Não se pode pensar em irogonomi sem pensar em senso estético, e mesmo nesse aspecto, o fato de o gosto de Kenkô ser refinado e apurado e possuir um agudo senso estético, capaz de distinguir o verdadeiro e o essencial, fica claro numa primeira leitura de Tsurezuregusa.

De que maneira estará, então, expresso o irogonomi de Kenkô na obra Tsurezuregusa?

Não se pode ignorar o seguinte trecho do capítulo 3:

Yorozuni imijikutomo irokonomazaran otokowa ito sôzôshiku tamano sakazukino sokonaki kokochizo subeki.

(Um homem pode ser excepcional em tudo, mas se não consegue se entregar ao amor /=homem que nāo é irogonomi/, ele é incompleto, assemelhando-se a uma magnífica taça sem fundo.)

8. Shumi ren'ai - literalmente "amor bom gosto", ou seja, o amor baseado não só no romance, mas também no senso estético e numa profunda cultura. (N. da T.) 
Kenkô considera ser natural e desejável o amor entre o homem e a mulher.

Não é muito difícil também retirar de Tsurezuregusa a visão de Kenkô sobre a figura feminina. $O$ fato de a mulher constituir uma grande tentação para o homem, encontra-se expresso da seguinte maneira:

Kisaragi jûgonichi tsuki akaki yo uchifukete Senbonno terani môdete ushiroyori irite hitori kao fukaku kakushite chômon shihaberishini yûnaru onnano sugata nioi hitoyori kotonaruga wakeirite hizani ikakareba nioinadomo utsurubakari nareba bin'ashito omoite surinokitaruni nao iyorite onaji sama tachinu. (Capítulo 238)

(No dia 15 do segundo mês /data da morte de Buda/, numa clara noite de luar, visitei tarde da noite, um templo em Senbon e, entrando pelos fundos, ouvia o culto, ocultando profundamente o meu rosto, quando uma fina mulher, que se destacava das demais pela beleza e a aparência, foi abrindo caminho entre os fiéis e recostou-se nos meus joelhos. Temendo que o perfume das suas vestes passasse para as minhas, afastei-me para um outro lugar, mas ela me seguiu e continuou agindo da mesma maneira, razão pela qual levantei-me e saí do local.)

Fica-se sabendo depois, que isso fora planejado por uma certa pessoa que, assentado no local reservado aos nobres, descobrira Kenkô na multidão e enviara uma de suas damas de companhia, especialmente adornada, para perto de Kenkô, a fim de testar a sua reação.

Ainda no capítulo 8 encontramos o seguinte trecho:

Yono hitono kokoro madowasu koto shikiyokuniwa shikazu. Hitono kokorowa orokanaru monokana. Nioinadowa karino mono naruni shibaraku ishôni takimonosuto shirinagara enaranu nioiniwa kanarazu kokoro tokimekisuru mono nari. Kumeno senninno mono arau onnano hagino shirokio mite tsûo ushinaikenwa makotoni teashi hadaenadono kiyorani koe abürazukitaranwa hokano iro naraneba samo arankashi.

(Nada perturba mais o sentimento das pessoas do que o desejo sexual. Quão tolo é o coraçāo do homem! Embora o odor seja algo passageiro, mesmo sabendo que o perfume do incenso nas roupas é momentâneo, certamente o coração baterá mais forte, quando se sente um perfume fino. É compreensível o fato de o homem santo de Kume ter perdido os seus poderes mágicos, ao contemplar as alvas pernas de uma jovem que lavava roupas, visto que os belos e carnudos braços e pernas, a pele não são nada mais do que a beleza carnal da mulher.)

A mulher é, dessa forma, atraente, sendo próprio do ser humano não resistir a essa tentação e não conseguir se libertar do desejo sexual.

Vejamos um trecho do capítulo 9:

Makotoni aijakuno michi sono ne fukaku minamoto tôshi. Rokujinno gyôyoku ooshito iedomo mina enri shitsubeshi. Sono nakani tada kano madoino hitotsu yamegatakinomizo oitarumo wakakimo chi arumo orokanarumo kawaru tokoro nashito miyuru.

(A paixão possui realmente raízes profundas e não pode ser explicada. Mesmo que se diga que os desejos oriundos dos seis sentidos humanos /visão, audição, olfato, gustação, tato e desejo/ são muitos, é possível afastar-se deles. $O$ fato de não conseguir controlar apenas um deles, o da atração pelo sexo oposto, é comum ao velho ou o jovem, ao sábio ou ao tolo.) 


\section{Com referência à mulher, encontramos os seguintes trechos:}

Subete onokooba onnani warawarenuyôni ooshi tatsubeshitozo. (Capítulo 107)

(Diz-se que o correto é que todos os meninos devem ser educados de forma a não serem zombados pelas mulheres.)

Ou ainda,

Onnano naki yo nariseba emonmo kôburimo ikanimo are hikitsukaurou hitomo haberaji. (Capítulo 107)

(Com certeza não haveria ninguém que se importasse com o modo de se vestir ou de usar o kanmuri ${ }^{9}$, se nesse mundo não houvesse mulheres.)

São trechos que, aparentemente, exaltam a figura feminina, mas não se trata disso absolutamente. Na continuação do mesmo capítulo, encontramos o seguinte trecho:

Kaku hitoni hajiraruru onna ikabakari imijiki monozoto omouni onnano sagawa mina higameri. Ningano sô fukaku ton'yoku hanahadashiku monono kotowario shirazu tada mayoino katani kokoromo hayaku utsuri kotobamo takumini kurushikaranu kotoomo tou tokiwa iwazu. Yôi anukato mireba mata asamashiki kotomade towazu katarini ïdasu. Fukaku tabakari kazareru kotowa otokono chienimo masaritarukato omoeba sono koto atoyori arawaruruo shirazu. Sunao narazushite tsutanaki monowa onnanari. Sono kokoroni shitagaite yoku omowaren kotowa kokoroukarubeshi. Sareba nanikawa onnano hazukashikaran. Moshi kenjo araba soremo monoutoku susamajikarinan. Tada mayoio arujito shite kareni shitagau toki yasashikumo omoshirokumo oboyubeki kotonari.

(Pensa-se quão maravilhosas sāo as mulheres assim exaltadas, mas na realidade, possuem um caráter falso. Elas são profundamente egoístas, extremamente ávidas e insatisfeitas, são insensatas, seus sentimentos tendem rapidamente a se voltarem somente para as práticas não condizentes com o Budismo e, embora tagarelas, quando indagadas, não respondem mesmo aquilo que devem responder. Quando se pensa que se calam por precaução, logo começam a tagarelar bobagens, mesmo sem serem solicitadas. Quando se pensa que elas são superiores aos homens, ao manterem uma aparência, sendo discretas, nem percebem quando essa fachada é descoberta. A mulher é a própria desonestidade e mediocridade. É tolice agir conforme mulheres assim, querendo agradá-las. Por isso, por que haveria a necessidade de preocupar-se com as mulheres? Por outro lado, se houver uma mulher inteligente certamente será insociável e insuportável. Somente quando o homem, cego de paixão, entrega-se e age conforme as vontades da mulher, é que a mulher the parece admirável e divertida.)

Trata-se de uma dura crítica à mulher. Kenkô diz que, mesmo o conhecimento de que a atração pela mulher em si é a perdição, o homem não consegue vencer a força do desejo que o empurra para essa direção.

Como seria, então, a forma do amor ideal?

9. Kanmuri - espécie de chapéu utilizado pelos nobres. Faz parte do traje de cerimônia. (N. da T.) 
Hisashiku otozurenu koro ikabakari uramuranto waga okotari omishirete kotonoha naki kokochisuruni onnano katayori - jichôya aru hitori - nado ïokosetarukoso arigataku ureshikere. Saru kokorozama shitaru hitozo yokito hitono môshihaberishi samo arubeki kotonari. (Capítulo 36)

(Concordo plenamente com o que disse uma certa pessoa: "Tinha passado um longo tempo desde que visitar pela última vez a casa da amada e pensava em como ela devia estar me odiando. Reconhecendo eu próprio o exagero da minha negligência e estando sem saber como me justificar, ela mandou-me uma mensagem dizendo - Você tem serviçais? Se tiver, mande-me um - criando, assim, uma oportunidade inesperada, o que me deixou feliz. Mulheres com esse tipo de natureza são desejáveis.)

Trata-se de um ideal de mulher bastante conveniente, sob o ponto de vista masculino, mas não há dúvida de que uma pessoa que age despretenciosamente, conforme a circunstância ou segundo a expectativa da outra parte, é um ideal não obrigatoriamente exclusivo de Kenkô.

No capítulo 137 onde pode-se vislumbrar, em particular, o senso estético de Kenkô, há também o pensamento referente ao amor:

Hanawa sakarini tsukiwa kumanakionomi miru monokawa. /.../ Yorozuno kotomo hajime owarikoso okashikere. Otoko onnano nasakemo hitoeni aiminuoba iumonokawa. Awade yaminishi usao omoi adanaru chigirio kakochi nagaki yo'o hitori akashi tôki kumoio omoiyari asajigayadoni mukashio shinobukoso irokonomuyowa iwame.

(Apreciamos nós a cerejeira somente quando ela está no seu auge do florescimento e a lua somente quando não há uma só nuvem no céu? /Não, em qualquer processo, em qualquer condição e beleza se faz presente./ /.../ Em todas as coisas, o princípio e o fim é que são interessantes. Em se tratando do amor entre o homem e a mulher, chamaríamos de amor somente o momento em que os amantes se encontram para se amar? /Não, não é isso./ Aquele que pensa na tristeza de um amor desfeito, lamenta um juramento quebrado, passa a longa noite sozinho, vive com o pensamento distante, voltado para a casa da amada, recorda o passado, quando manteve encontros com a amada numa casa em ruínas, este sim, compreende os deleites do amor /ou seja, é irogonomi/.)

Segundo Kenkô, ser capaz de apreciar os deleites do amor desencontrado, do amor infrutífero, do amor desfeito é o verdadeiro irogonomi.

Kenkô que é eremita budista é contrário ao casamento.

Meto iu monokoso onokowa motsumajiki mononare. "Itsumo hitorizuminite" nado kikukoso kokoro nikukere. "Taregashiga mukoni narinu" tomo mata "Ikanaru onnao torisuete aisumu" nado kikitsureba mugeni kokoro otoriseraruru wazanari. Kotonaru koto naki onnao yoshito omoisadametekoso soiitarameto iyashikumo oshihakarare yoki onnanaraba kono otokoozo rôtakushite aga hotoketo mamori itarame tatoeba sabakarinikosoto oboenubeshi. Mashite ieno uchio okonai osametaru onna ito kuchioshi. Konado idekite kashizuki aishitaru kokoroushi. Otoko nakunarite nochi amani narite toshiyoritaru arisama naki atomade asamashi. Ikanaru onnanaritomo akekure soiminniwa ito kokorozukinaku nikukarinan. Onnano tamemo nakazoranikoso narame. Yosonagara tokidoki kayoisumankoso toshitsukihetemo taenu nakarai tomonarame. Akarasamani kite tomarïnado senwa mezurashikarinubeshi. (Capítulo 190)

(Um homem nunca deverá ter uma esposa. Agrada-me muito ouvir alguém dizendo: "Viverei sempre s6". Quando ouço alguém dizendo: "Tornou-se genro de Fula- 
no" ou ainda "Trouxe uma mulher assim, assim e estão vivendo juntos", surge em mim um forte sentimento de desprezo. As pessoas podem imaginar simplesmente: "Deve estar junto a uma mulher insignificante, achando que é maravilhosa" ou ainda, no caso de ser uma mulher virtuosa, "Ela deve tratá-lo com carinho e ser-lhe devotada como se ele fosse seu Buda", em outras palavras, provavelmente isso é o máximo que pensarāo. É ainda pior quando se trata de mulher que mantém o controle da casa. É lamentável vêla desdobrar-se em criar os filhos. É consternador assistir a mulher tornar-se monja $e$ ir envelhecendo, depois da morte do marido. Qualquer que seja a mulher, acabará, provavelmente, sendo rejeitada e odiada se a relaçāo implicar numa convivência diária e prolongada. A própria mulher deve se sentir insegura. Um relacionamento duradouro deve ser aquele que, o casal morando separado, o homem a visita ocasionalmente. Não há dúvida de que uma repentina visita para passar alguns momentos juntos reaviva o relacionamento.)

A negação do lar e da familia é natural do eremita, mas o fato de não negar o amor suscita interesse. Para manter o sentimento amoroso é preciso evitar o casamento. No final do capítulo 240 encontramos também uma opinião contrária ao casamento, e a conclusão a que se chega é a seguinte:

Umeno hana kôbashiki yono oborozukiyoni tatazumi mikakigaharano tsuyu wakeiden ariakeno soramo waga mizamani shinobarubekumo nakaran hitowa tada irokonomazaranniwashikaji.

(Um homem que não tenha passado por experiências tais como o de deter-se numa noite de lua enevoada, em que pairava no ar a fragrância da ameixeira, ou de passar pelos orvalhos do jardim da casa da amada, quando retornava para casa ao romper do dia /deleites amorosos típicos das narrativas clássicas/, melhor será se não tiver nada com o amor.)

Kenkô que descobriu várias facetas interessantes do ser humano como a harmonia ou a contradição, justamente no relacionamento entre o homem e a mulher, não nega o amor. Entretanto, o casamento que ele abandonou como sendo um hábito do mundo terreno, contraria o senso estético do irogonomi. A instituição do casamento acaba destruindo o mundo do irogonomi que zela pelo deleite amoroso e preserva sempre o sentimento amoroso. Deve ser essa uma conclusão tirada da própria experiência de Kenkô. Não há dúvida de que Kenkô manteve um relacionamento sincero e fervoroso com alguma mulher, e possui a experiência de ter passado por um sério envolvimento amoroso. Provavelmente enfrentou discórdias e passou por sofrimentos. A conclusão a que chegou, depois de divisar vários modos de vida, inclusive a própria experiência foi: a negação do casamento e a afirmação do irogonomi.

Entretanto, considerando-se que a negação do casamento é natural em se tratando de um eremita, o irogonomi não seria contraditório à reclusão religiosa? Onde estará a harmonia? Tratemos, a seguir, sobre a visão de reclusão religiosa de Kenkô. 
Como já foi mencionado no nosso trabalho, o ponto em comum entre os três tipos dé reclusão religiosa é o isolamento. $O$ eremita budista desligase da familia, dos parentes e do mundo e o isolamento é um requisito importante. Naturalmente, encontramos freqüentemente mencionado os méritos do isolamento em Tsurezuregusa.

Inicialmente, na parte introdutória, encontra-se exposta a postura de escrita relacionada com o estado do tsurezure ( = a monotonia do far-niente), escolhido voluntariamente.

Tsurezure narumamani hi kurashi suzurini mukaite kokoroni utsuriyuku yoshinashigotoo sokohakatonaku kakitsukureba ayashakoso monoguruoshikere.

(Anotando despropositadamente as divagaçōes que vão e vêm na mente, levado pelo ócio, e tendo à frente o suzuri ${ }^{10}$, uma estranha sensação de insensatez invade-me a alma.)

A própria obra Tsurezuregusa foi escrita na solidão do confinamento. A vida de confinamento é a vida desejável.

Tsurezure waburu hitowa ikanaru kokoronaran. Maginuru katanaku tada hitori arunomikoso yokere.

Yoni shitagaeba kokoro hokano chirini ubawarete madoiyasuku hitoni majiwareba kotoba yosono kikini shitagaite sanagara kokoroni arazu. Hitoni tawabure mononi arasoi hitotabiwa urami hitotabiwa yorokobu. Sono koto sadamareru koto nashi. Funbetsu midarini okorite tokushitsu yamu koto nashi. Madoino ueni yoeri. Yoino ueni yumeo nasu. Hashirite isogawashiku horete wasuretaru koto hito mina kakuno gotoshi.

Imada makotono michio shirazutomo en'o hanarete mio shizukani shi kotoni azukarazushite kokoroo yasuku senkoso shibaraku tanoshibutomo ütsubekere. "Shôkatsu ninji ginó gakumonnadono shoen'o yameyo" tokoso Makashikannimo habere. (Capítulo 75)

(Não consigo entender aś pessoas que sofrem por estarem sós e não terem o que fazer. $\mathrm{O}$ bom mesmo é ter a mente livre de qualquer desvio e manter-se isolado. Se você age conforme a sociedade, o seu espírito estará mais suscetivel às sujeiras do mundo externo, e se você mantém um relacionamento social, no seu esforço de não ferir as pessoas, você acaba falando aquilo que vai contra o seu verdadeiro sentimento. Você brinca, discute com as pessoas, às vezes, odeia, às vezes, alegra-se. Não existe sossego espiritual assim. Há uma constante preocupação com perdas e ganhos. À ilusão soma-se a embriaguez, e neste estado de inebriamento, você sonha. As pessoas são todas assim: vivem agitadas e atarefadas, esquecidas da própria essência.

Mesmo não tendo alcançado ainda a iluminaçāo espiritual, desligar-se do mundo terreno, levar uma vida tranqüila $e$ ter paz de espírito $\ell$ desfrutar, por um breve tempo que seja, a vida. Está escrito no Makashikan"1: "Corte todos os elos - com a vida cotidiana, com as relaçōes sociais, com as artes, com os estudos").

Kenkô explica que só no isolamento da reclusão será possível esquivar-se das ilusões como o sonho ou a embriaguez, alcançar a liberdade de espírito e conhecer a própria essência.

10. Suzuri - uma espécie de tinteiro onde se raspa a barra de nanquim sólido com água, para se obter a tinta líquida.

11. Makashikan - texto do Budismo Tendai. 
Kenkô escreve:

Hitori tomoshibino motoni fumio hirogete minu yono hitoo tomoto suruzo koyonô nagusamu wazanaru. (Capítulo 13)

(Um especial prazer para o espírito é sentar-se sozinho, sob a luz da lamparina e, abrindo um livro, tornar-se amigo de pessoas que viveram num remoto passado.)

Ou ainda,

Shizukani omoeba yorozu suginishikatano koishisanomizo senkatanaki.

Hito shizumarite nochi nagaki yono susabini nanito naki gusoku torishitatame nokoshiokajito omou hógonado yarisutsuru nakani naki hitono tenarai e kakisusabitaru miidetarukoso tada sono orino kokochisure. Konogoro aru hitono fumidani hisashiku narite ikanaru ori itsuno toshinarikento omouwa awarenaruzokashi. Tenareshi gusokunadomo kokoromo nakute kawarazu hisashiki ito kanashi. (Capítulo 29)

(Quando estou meditando silenciosamente, entre todas as coisas, o mais difícil de controlar é a saudade do passado. Quando todos dormem, passo as longas noites distraindo-me em ordenar os objetos à minha volta e, quando, misturado entre os papéis inutilizados que rasgo para jogar fora, descubro exercícios de caligrafia ou um desenho feito à guisa de distraçāo, pertencentes a um amigo já falecido, sinto como se voltasse àquele momento do passado. Mesmo em se tratando de cartas de pessoas ainda vivas, sinto uma forte emoçāo ao recordar, depois de algum tempo, em que circunstâncias, em que data foram escritas. É muito doloroso pensar que os pertences de um homem restam indiferentemente inalterados, mesmo após a sua morte.)

O processo percorrido até a opção pelo isolamento não deve ter sido absolutamente simples para Kenkô. Pode-se, no entanto, considerar como uma das causas principais o problema do distanciamento social.

Manter um distanciamento ideal entre as pessoas é bastante complicado. $O$ referencial de um distanciamento agradável varia consideravelmente, segundo o país ou a cultura. Se há um distanciamento excessivo, há um isolamento que traz a solidão, mas uma excessiva intromissão é desagradável, chegando, por vezes, a magoar. Nem é preciso dizer que o mesmo acontece com o relacionamento entre o homem e a mulher. Parece que uma das preocupações de Kenkô consistia em como manter num estado desejável o equilíbrio entre o seu interior e o exterior, representado pelo relacionamento social. Imagina-se que a reclusão religiosa de Kenkô previa meios de solução para preservar, de forma ideal, a distância entre o "eu" e os "outros"

A seguir, vejamos qual foi o processo seguido por Kenkô para optar pelo isolamento, relacionado com o interior do "eu" e o relacionamento social exterior.

Inicialmente, é extremamente difícil para o homem conhecer-se a si próprio. Torna-se complexo avaliar corretamente a própria posição e viver conhecendo-se a si próprio no mundo terreno.

Takakurainno Hokkedôno sanmaisô nanigashino risshitoka iu mono aru toki kagamio torite kaoo tsukuzukuto mite waga katachino minikuku asamashiki kotoo amarini kokorouku oboete kagamisae utomashiki kokochi shikereba sono nochi nagaku kagamio 
osorete tenidani torazu sarani hitoni majiwaru koto nashi. Midôno tsutomebakarini aite komori itarito kikihaberishikoso arigataku oboeshika.

Kashikogenaruhitomo hitono uenomio hakarite onoreoba shirazarunari. Wareo shirazushite hokao shiruto iu kotowari arubekarazu. Sareba onoreo shiruo mono shireru hitoto iubeshi. Katachi minikukeredomo shirazu kokoroo orokanaruomo shirazu geino tsutanakiomo shirazu kazu naranuomo shirazu toshino oinuruomo shirazu shino chikaki kotoomo shirazu okonau nichino itarazuomo shirazu. Mino ueno hio shiraneba mashite hokano soshirio shirazu. Tadashi katachiwa kagamini miyu. Toshiwa kazoete shiru. Waga mino koto shiranuniwa aranedo subeki katano nakereba shiranuni nitaritozo iwamashi. Katachio aratame yowaio wakaku seyotoniwa arazu. Tsutanakio shiraba nanzo yagate nokazaru. Oinuruto shiraba nanzo shizukani ite mio yasuku sezaru. Okonai orokanarito shiraba nanzo koreo omoukoto koreni arazaru.

Subete hitoni aikyô serarezushite shûni majiwaruruwa hajinari. Kaiachi minikuku kokoro okurenishite idetsukae muchinishite taisaini majiwari fukanno geio mochite kannôno zani tsuranari yukino kashirao itadakite sakarinaru hitoni narabi iwanya oyobazaru kotoo nozomi kanawanu kotoo uree kitarazaru kotoo machi hitoni osore hitoni koburuwa hitono atauru hajini arazu. Musaboru kokoroni hikarete mizukara mio hazukashimurunari. Musaboru kotono yamazaruwa inochio ouru daiji ima kokoni kitarerito tashikani shirazarebanari. (Capítulo 134)

(Um certo sacerdote asceta, um monge samádi12, do Pavilhão Hokke, onde estão guardados os restos mortais do Imperador Enclausurado Takakura, pegou, certa vez, um espelho e contemplou cuidadosamente o próprio rosto. Extremamente decepcionado com a fealdade e a asquerosidade do seu rosto, ficou longo tempo, depois disso, temeroso de se olhar no espelho, evitando mesmo de tocá-lo e esquivava-se de qualquer relacionamento social. Participava somente dos serviços religiosos do Pavilhão e, de resto, mantinha-se recluso. Quando ouvi isso, achei inimitável e admirável.

Mesmo as pessoas que parecem inteligentes julgam os outros, sem conhecerem a si próprias. Não existe logicidade no fato de conhecer os outros, sem se conhecer a si próprio. Por isso, podemos afirmar que conhecer-se a si próprio é conhecer a lógica das coisas. As pessoas não sabem que são feias, que são tolas, que são inaptas, que são insignificantes, que são velhas, que estão doentes, que estão d̀s portas da morte, nem que seus conhecimentos sobre o Budismo sāo insuficientes. Como não conhecem os próprios defeitos, não conhecem naturalmente as censuras da sociedade contra si. Entretanto, o rosto reflete-se no espelho. A idade conhece-se pela contagem. Por isso, não significa que as pessoas não se conheçam a si próprias. Mas alguém poderá dizer. "É o mesmo que não se conhecer, pois não se pode fazer nada contra isso." Eu não estou dizendo para melhorar o rosto ou para rejuvenescer. $O$ que quero dizer 6 : se souber que não é capacitado, por que não se retira? Se achar que está velho, por que não vive tranqüilamente, poupando-se? Se sentir que não está se devotando suficientemente, por que não reflete bem sobre isso?

E uma vergonha relacionar-se com as pessoas sem que elas o amem ou aceitem. Se vocḱ, embora feio e medíocre, presta serviços ao governo; se você, mesmo ignorante, envolve-se com os intelectuais; se você, sem talento, acompanha as pessoas talentosas; se você, embora sendo um velho de cabelos brancos, quer competir, lado a lado, com aqueles que estão no auge da atividade e, se você, desejando coisas absurdas, entristece-se quando as coisas não caminham conforme o esperado, anseia por algo irrealizável, teme $e$ adula as pessoas, a vergonha $\epsilon$ a conseqüência natural dos próprios atos. É a desonra própria causada pela ganância. A nossa ganância não tem fim, porque nāo está claro na nossa mente, que o grande evento denominado morte está bem à nossa frente.)

12. Monge samádi - refiro-me ao monge da seita Tendai que alcançou o samádi, através da leitura do Sutra Hokke. (N. da T.) 
Relacionar-se com as pessoas conhecendo-se a si próprio é raríssimo, razão pela qual a proximidade física não indica uma proximidade espiritual, tornando as pessoas ainda mais solitárias.

Onaji kokoro naran hitoto shimeyakani monogatarishite okashiki kotomo yono hakanaki kotomo uranaku ii nagusamankoso ureshikarubekini saru hito arumajikereba tsuyu tagawazaranto mukaitaranwa hitori aru kokochiyasen. (Capítulo 12)

(Se houver alguém em completa afinidade com você, não haveria alegria maior se pudesse confortar a alma, conversando intimamente, trocando idéias abertamente sobre assuntos interessantes ou banais, mas tal pessoa é difícil de se encontrar. Por isso, conversar com alguém, medindo as palavras para nāo contrariá-lo, provavelmente fará nascer o sentimento de solidão.)

É raro encontrar alguém adequado e ideal. É desgastante e desvantajoso para os dois lados, por isso convém afastar-se das pessoas.

Sashitaru koto nakute hito nogari yukuwa yokaranu kotonari. Yô arite ikitaritomo sono koto hatenaba toku kaerubeshi. Hisashiku itaru ito mutsukashi.

Hitoto mukaitareba kotoba ooku mimo kutabire kokoromo shizukanarazu. Yorozuno koto sawarite tokio utsusu tagaino tame yaku nashi. Itooshigeni iwanmo waroshi. Kokorozukinaki koto aran oriwa nakanaka sono yoshiomo iiten. Onaji kokoroni mukawamashiku omowan hitono tsurezurenite - Ima shibashi. Kyôwa kokoro shizukani - nado iwanwa kono kagiriniwa arazarubeshi. Gensekiga aoki manako taremo aru bekikotonari.

Sono kotonakini hito kitarite nodokani monogatarishite kaerinuru ito yoshi. Mata fumimo - Hisashiku kikoe saseneba - nadobakari iiokosetaru ito ureshi. (Capítulo 170)

(Não é recomendável visitar alguém sem um propósito definido. Mesmo tendo um propósito, é apropriado retirar-se tão logo o. assunto seja resolvido. A longa permanência é um incômodo.

Quando se está diante de alguém, as palavras fluem, fica-se fatigado e intranqüilo. É uma insensatez para ambos desperdiçar o tempo em detrimento de tudo. Não é também aconselhável conversar forçadamente. Quando houver algo que não lhe interessa, melhor será éxpor esse motivo francamente. Constitui-se exceção o caso em que alguém que você sente afinidade está sem ter o que fazer e lhe diz: "Fique mais um pouco. Hoje vamos conversar calmamente." Dizem que o sábio Genseki ${ }^{13}$ recebia as pessoas queridas com "olhos verdes", e isso pode acontecer com qualquer pessoa. É bastante agradável, quando ao não termos nada em especial para fazer, alguém nos visita, conversa tranqüilamente e retira-se. Fico também muito contente quando recebo uma carta, dizendo simplesmente: "Estou lhe escrevendo, pois há muito que não lhe escrevo".)

Kenkô não se baseia unicamente em argumentos capciosos para manter distância das pessoas, mas zela pelo relacionamento com pessoas com que se dá bem ou que sente afinidade. Pessoas que se encaixem nesse tipo de visão de homem ou senso estético são raras, mas não são completamente inexistentes.

13. Genseki - ermitão que viveu na China (210-263). Foi um dos Sete Sábios da Floresta de Bambu. Conta-se que ele selecionava as visitas, recebendo com "olhos verdes" (olhos límpidos de satisfação) as que lhe eram bem-vindas e com "olhos brancos", indicando o olhar voltado para cima, olhar de indiferença), as indesejáveis. (N. da T.) 
Yukino omoshirô furitarishi ashita hitonogari iubeki koto arite fumi yarutotote yukino koto nanitomo iwazarishi kaerigotoni - Kono yuki ikaga minuto hitofude notamawasenuhodono higahigashikaran hitono ooseraruru koto kikiirubekikawa. Kaesugaesu kuchioshiki mikokoronari - to iitarishi koso okashikarishika.

Imawa naki hito nareba kabakarino kotomo wasure gatashi. (Capítulo 31)

(Numa bela manhã de neve, precisando tratar de um assunto, enviei uma carta a uma certa pessoa, mas esqueci de mencionar sobre a neve. A resposta que recebi achei interessante: "Poderia eu tratar algum assunto, com alguém tão insensível, a ponto de nem me perguntar o que achei da neve? É algo lamentável!"

Quem escreveu essa carta já faleceu, razão pela qual guardo esse pequeno ocorrido na minha mente.)

\section{Encontramos ainda no capítulo 32:}

Nagatsuki hatsukano koro aru hitoni sasowaretatematsurite akurumade tsuki miaruku koto haberishini oboshi izuru tokoro arite anai sesasete iritamainu. Aretaru niwano tsuyu shigekini wazato naranu nioi shimeyakani uchikaorite shinobitaru kehai ito mono awarenari.

Yokihodonite idetamainuredo nao kotozamano yûni oboete monono kakureyori shibashi miitaruni tsumadoo ima sukoshi akete tsuki minu keshikinari. Yagate kakekomorashikaba kuchioshikaramashi. Atomade minu hito aritowa ikade shiran. Kayôno kotowa tada asayûno kokorozukaini yorubeshi. Sono hito hodonaku usetarito kikihaberishi.

(Aproximadamente no dia vinte do nono mês, a convite de um certo cavalheiro, fiz um passeio noturno contemplando a lua até o amanhecer. Mas durante o passeio, lembrando-se repentinamente de uma certa residência, ele se fez anunciar e adentrou nela. $O$ jardim abandonado estava coberto de orvalhos e sentia-se eventualmente, no ar, a suave fragrância do incenso, e esse aspecto de viver como num retiro emocionou-me bastante.

$A$ pessoa retirou-se da residência no devido tempo, mas eu permaneci ainda algum tempo, apreciando a elegante atmosfera da casa, acobertado pela vegetação, quando vi uma jovem que parecia estar admirando a lua pela fresta da porta dupla. Se, logo após a retirada da visita, ela tivesse fechado a porta e se recolhido, seria lastimável. Como ela poderia adivinhar que alguém a observava, depois da partida da visita? Esses atos são resultados unicamente de um agir do cotidiano. Ouvi dizer que essa jovem falecera algum tempo depois.)

A disponibilidade e a prudência que não negligenciam e zelam pelos mínimos atos não se adquirem da noite para o dia, são produtos de umá rica cultura e vasto conhecimento. As pessoas citadas nos capítulos 31 e 32 devem ser mulheres que viveram cuidadosamente a breve existência e são as duas agora já falecidas.

O que se observa é que as pessoas que personificam, dessa forma, o ideal, são pessoas já falecidas; o companheiro ideal para conversas é também alguém já falecido (capítulo 29) ou alguém do remoto passado (capítulo 13), ou seja, não são pessoas pertencentes a este mundo terreno.

Respeitar e valorizar a cultura do passado remoto, ou seja, a postura de devoção do clássico é vista em todo o Tsurezuregusa. $\mathrm{O}$ mesmo acontece com relação ao distanciamento ideal entre as pessoas. Era muito difícil para Kenkô descobrir a figura ideal no mundo terreno real. Ele não podia deixar de rejeitar o fato de ficar submerso nesse mundo terreno repleto de pessoas 
superficiais que não conhecem a si próprias e deficitário em se tratando de companheiros que compartilham os mesmos sentimentos. E o seu olhar volta-se naturalmente em direção ao magnífico passado. $O$ irogonomi ideal, buscado por ele, raramente é encontrado na realidade. Kenkô que nega o sistema matrimonial de convivência diária, anulador do deleite amoroso e da paixão vigorosa, anseia pelo mundo do amor clássico. Desde que sẹ encontre limitado pelo juízo de valor do mundo terreno, não existe a liberdade espiritual. A disponibilidade para apreciar o senso estético do irogonomi e a vida não pode ser concretizada na relação com pessoas reais. Kenkô optou pelo isolamento, libertou o ego no mundo da devoção do clássico e aproveitou a liberdade nesse mundo espiritual. $O$ infinito interesse pelo ser humano e o profundo discernimento originais não diminuiriam com a reclusão religiosa. $\mathrm{O}$ espírito livre torna possível perceber a essência e a verdade das coisas. $\mathrm{O}$ isolamento é o único caminho para aproximar-se da essência do modo de ser do homem.

A reclusão religiosa e o irogonomi, que parecem contraditórios sob o ponto de vista atual, são dois grandes fatores que mostram a essência do modo de vida de Kenkô. A riqueza e o alto grau de refinamento do irogonomi, a elegância do gosto não são absolutamente contraditórias com a liberdade da reclusão religiosa e a profundidade do discernimento com relação ao homem e às coisas. Só com a liberdade espiritual é que se compreende, pela primeira vez, a essência do irogonomi e se domina o seu senso estético. 